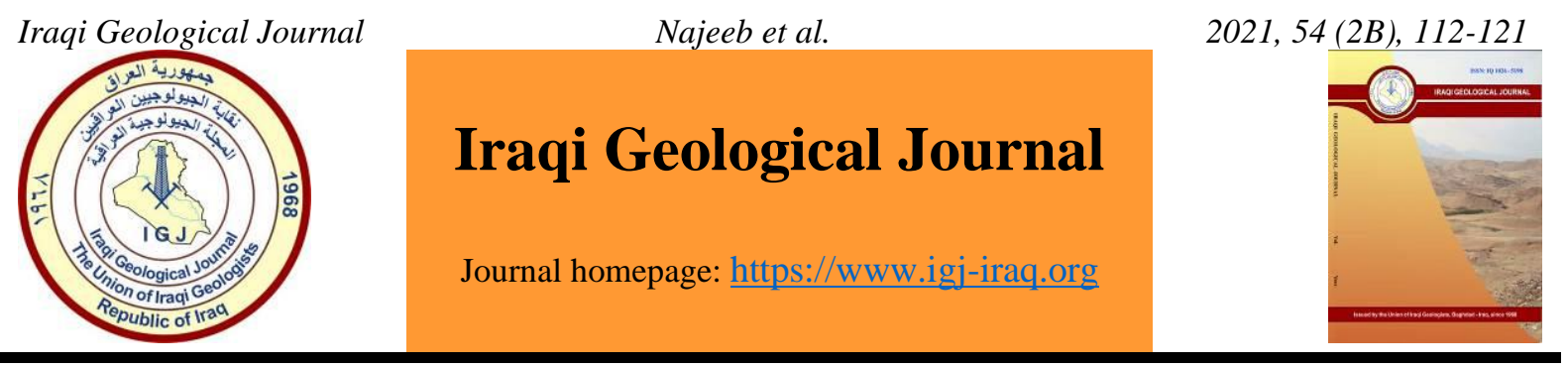

\title{
Hydrogeology of Al-Hamdaniya, Northern Iraq
}

\author{
Fadi Raed Najeeb ${ }^{1, *}$, Sabbar Abdulla Saleh ${ }^{1}$ and Mahmood Fadhil Abed ${ }^{1}$ \\ ${ }^{1}$ Department of Applied Geology, College of Science, University of Tikrit, Tikrit, Iraq \\ * Correspondence: fadi-2555@yahoo.com
}

Received: 24 May 2021; Accepted: 4 July 2021; Published: 31 August 2021

\begin{abstract}
The current study evaluated the hydrogeological conditions and hydraulic properties of the groundwater aquifers in Qaraqosh, Karamless and Bartella areas within Al-Hamdaniya district east Mosul. The depths and water tables of groundwater for 48 well were measured in October 2019, were ranged between 5 - 45 meters and $234-278.5$ meters, respectively. The highest water table reaches in the center of the studied area north Qaraqosh and decreases gradually in all directions. A map of the flow net was drawn, and it was found that the general direction of water movement is from north to south, with local directions resulting by pumping from the aquifer, or due to the heterogeneity of the porous media. The results of the pumping test in Karamless area shows that the transmissivity was $107.671 \mathrm{~m}^{2} /$ day and $100.682 \mathrm{~m}^{2} /$ day according to Theis and Cooper-Jacob methods, respectively. The hydraulic conductivity of $157.65 \mathrm{~m}$ saturated thickness was found to be $0.683 \mathrm{~m} /$ day and 0.639 $\mathrm{m} / \mathrm{day}$ using Theis and Cooper-Jacob methods, respectively. While the storage coefficient using Theis and Cooper-Jacob methods was 0.0023 and 0.0020 ، respectively. In Qaraqosh, the transmissivity was $87.1685 \mathrm{~m}^{2} / \mathrm{day}$ and $88.1004 \mathrm{~m}^{2} /$ day according to the mentioned methods, respectively. While the hydraulic conductivity of saturated thickness of $71.07 \mathrm{~m}$ was found to be $1.24 \mathrm{~m} /$ day and $1.23 \mathrm{~m} /$ day using Theis and Cooper-Jacob methods, respectively. The values of storage coefficient using these methods was 0.00135 and 0.00115 respectively. The total dissolved solids (TDS) measured to conclude the hydrogeological system according to the quality of the groundwater aquifers, it was found that the concentrations of total dissolved solids are more than $3500 \mathrm{ppm}$ in the mid of the study area and decreased towards all directions to the limits of $250 \mathrm{ppm}$. This wide variation in salinity may be because the wells in the central area penetrate the groundwater aquifers, represented by the layers of gypsum in Al-Fat'ha formation, which is hydraulically connected with the main aquifer of the Injana formation.
\end{abstract}

Keywords: Groundwater; Qaraqosh; Karamless; Bartella; pumping test; TDS

\section{Introduction}

The main problem in all over the world is the supply of drinking water for domestic uses, as a result of the population increase, and that the gap between the water supply and the need of drinking water can expand and reach dangerous levels (Awadh et al., 2020). and may be considered a threat to human life (Yajingli and Kunpeng, 2009). The reports indicating that the next crises will be caused by water, although, the water is necessary for life, may be caused hazards if it is polluted (WHO, 2017). Consequently, the scarcity of fresh water can cause a severe problem all over the world because only

DOI: 10.46717/igj.54.2B.10Ms-2021-08-30 
about $1 \%$ of the water in the world is fresh and potable water (Pangorkar, et al. 2010), especially in the area with an arid or semi-arid climate, when the study area is locating with (Lamei, et al, 2008). The increasing population growth in Iraq, which reached to 40 million people in 2020, this increasing also happen in the studied area constitutes more pressures exhausting on water resources that have become scarce than ever before. The management of natural resources has not been sufficient for years ago. According to available estimates, the per capita of water in Iraq reaches 2,400 cubic meters annually. All this will lead to an increase the demand for water and agricultural production (USEPA, 2012). The importance of the hydraulic properties of an aquifer lies in determining some of the reservoirs' characteristics such as groundwater movement and recharge during the pumping process (Al-Kubaisi et al, 2018). The study area represented by Qaraqosh district, Karamless district, and Bartella district, with an area of $\left(130 \mathrm{~km}^{2}\right)$ located to the east of Mosul district and to the west of Erbil Governorate. Within the UTM coordinates in (346800) to (363000) east and (4007800) to (4030000) north, Fig. 1.

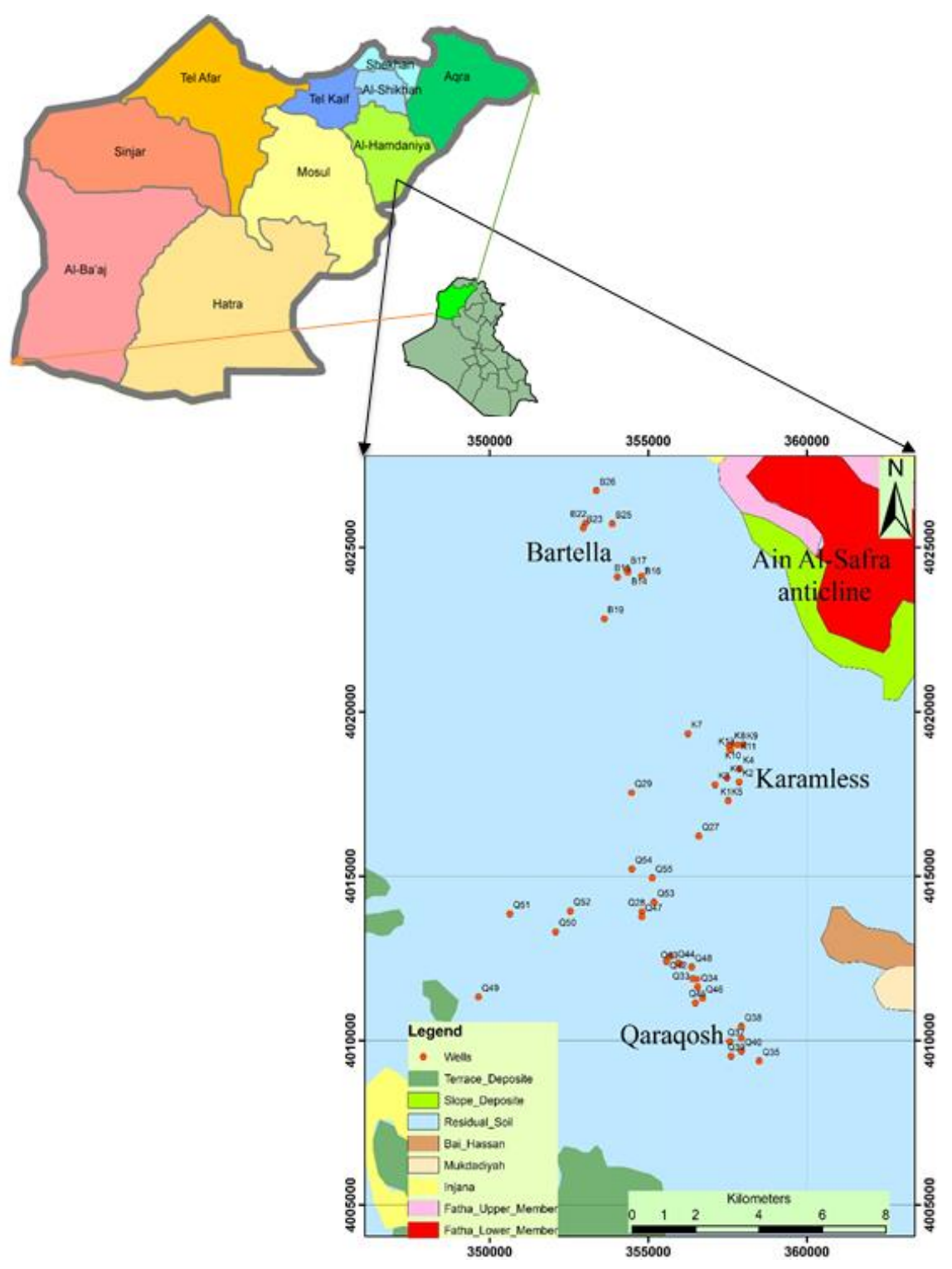

Fig. 1. Location and geological map of the study area 
Geomorphologically, the area bordered from the northeast by Ain Al-Safra anticline, Bashiqa and Al-Fadiliya anticline from the north, from the southeast the area bounded by Greater Zab River, and from the southwestern is bordered by the Tigris River. The area under study is important and promising in terms of the utilization of groundwater, which contributes to the expansion the agricultural area and also supply the needs of residential areas. Which required the study of the hydrogeological and hydraulic characteristics of the groundwater aquifers; consequently, it is used as a database to draw up a policy for investing this water for various purposes.

The study aims to define the hydrogeological system and the type of groundwater aquifers in the area, then, estimate the hydraulic characteristics of the aquifer using pumping test analyses, and identify the water bearing layers and formations, through the lithological description of the wells. The study also objects to monitor the depths to groundwater and derive the flow net using the data obtained from monitoring wells, determine the recharge and discharge areas.

\section{Materials and Methods}

The fieldwork included a first exploratory trip of the study location at the beginning of October 2019 , to identify the outcrops of geological formations, geomorphological and structural phenomena that related to the hydrogeological system, observation of major valleys, and determination of various field measurements. A second field tour was conducted in mid-October 2019, and lasted for more than a month, during which a field survey was conducted to view the geological and geomorphological features and determine the coordinates of the existing wells, using a Global Positioning System (GPS) (Table 1).

Table 1. The coordinates of the wells that have been studied

\begin{tabular}{ccccccccc}
\hline Well No. & X & Y & Well No. & X & Y & Well No. & X & Y \\
Karamless & & B20 & 355272 & 4025685 & Q40 & 357944 & 4009675 \\
K1 & 357526 & 4017293 & B21 & 354451 & 4025048 & Q41 & 355710 & 4012571 \\
K2 & 357872 & 4017865 & B22 & 353032 & 4025741 & Q42 & 355579 & 4012406 \\
K3 & 357110 & 4017784 & B23 & 352954 & 4025586 & Q43 & 356014 & 4012325 \\
K4 & 357887 & 4018252 & B24 & 353064 & 4026386 & Q44 & 355953 & 4012353 \\
K5 & 357525 & 4017292 & B25 & 353867 & 4025716 & Q45 & 356489 & 4011149 \\
K6 & 357485 & 4017990 & B26 & 353365 & 4026721 & Q46 & 356719 & 4011285 \\
K7 & 356257 & 4019337 & & Qaraqosh & & Q47 & 354800 & 4013763 \\
K8 & 357619 & 4018999 & Q27 & 356599 & 4016218 & Q48 & 356370 & 4012232 \\
K9 & 358007 & 4018992 & Q28 & 354808 & 4013922 & Q49 & 349649 & 4011322 \\
K10 & 357549 & 4018945 & Q29 & 354474 & 4017538 & Q50 & 352085 & 4013310 \\
K11 & 357826 & 4018990 & Q30 & 353911 & 4017276 & Q51 & 350642 & 4013855 \\
K12 & 358136 & 4019122 & Q31 & 354038 & 4017784 & Q52 & 352545 & 4013937 \\
K13 & 357595 & 4018827 & Q32 & 356532 & 4011868 & Q53 & 355186 & 4014205 \\
& Bartella & & Q33 & 356411 & 4011871 & Q54 & 354490 & 4015218 \\
B14 & 354361 & 4024240 & Q34 & 356560 & 4011627 & Q55 & 355127 & 4014941 \\
B15 & 354030 & 4024101 & Q35 & 358504 & 4009373 & - & - & - \\
B16 & 354796 & 4024128 & Q36 & 357938 & 4010066 & - & - & - \\
B17 & 354341 & 4024324 & Q37 & 357574 & 4009972 & - & - & - \\
B18 & 354717 & 4025439 & Q38 & 357939 & 4010421 & - & - & - \\
B19 & 353619 & 4022826 & Q39 & 357616 & 4009530 & & - & -
\end{tabular}

Groundwater depths were measured (for the period 10/10/2019 to 11/15/2019), using a groundwater depth detector, which measured from a fixed point on the ground surface, while, the heights of ground surface were determined using digital elevation model (DEM), by Global Mapper software. The samples were collected from 55 wells by poly ethaline bottles of 0.5 liter for testing the TDS to be used for hydrogeological description. The bottle was washed by the sample water for three times, and filling the bottles after 25 minutes pumping, in order to sampling from aquifer water. The bottles filled 
slowly to avoid the turbidity or bubbles, and then it was labeled by the name of the well owner, the number of the well, and the date of sampling, and then the samples kept in cold container, to avoid the qualitative changes, and then transfer the samples to the laboratory.

The specialized software package (Aquifer Win 32) was used in analyzing the pumping data, according to the methods and the examples contained in the documents accompanying the software, (Theis, 1935, Reed, 1980, Kruseman and Deridder, 1990). The total dissolved solids were measured in the laboratory using TDS measuring device. The measurement was made by shaking a quantity of the water sample in a glass beaker, and then placing the probe of the device in the sample.

\section{Results and Discussion}

\subsection{Water-Bearing Aquifers}

An aquifer can be defined as a layer or layers of rocks or sediments that have permeability and porosity that contain water in quantities that allow it to move through it under natural conditions (Todd, 2005). Unconfined aquifers generally accept recharge from the earth's surface over their entire stretch, while recharge to confined and semi-confined aquifers is restricted to areas where hydraulically permeable materials connect the aquifers to the land surface or upper aquifers (Richard, et al. 2019).

Through the study of the lithological sections of the drilled wells in the region, from the data bank of the General Authority for Groundwater in Nineveh, the lithological description for some wells were processed into Rockwork software to draw the lithological sections, (Fig. 2). The groundwater-bearing formations in the study area have been identified, represented by the formation of Injana, which represents the main aquifer is in the study area, and there is a secondary aquifer within the sediments of the Quaternary period it was found that most of the sediments are composed of sequences of mudstone, sandstone, and siltstones, and fine, coarse and sandy gravel rocks that interbeded with layers of sandy, clayey and Silty rocks. This aquifer can be considered (Aquisystem) consisting of (multi layers aquifer), due to the presence of permeable and impermeable rock units. Because of the difficulty of isolating these aquifers from each other during pumping test operations, what the results of pumping test operations give a final result of the characteristics of the aquifers that the wells penetrate. As the presence of mud layers extending for wide distances in the aquifer suggests the presence of confined aquifers, and it has also been observed that the water table is located within the boundaries of the clay layers confirms this result and therefore the combined aquifers may behave as semi-confined aquifers, this was confirmed by the results of the pumping test that was carried out on two wells in the study area.
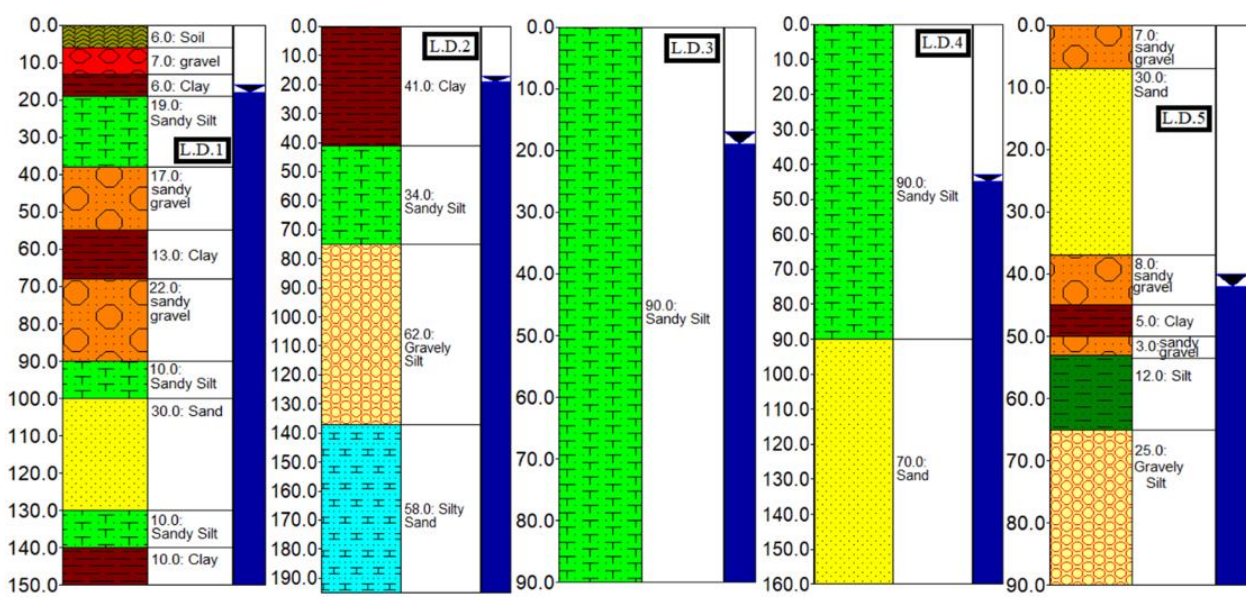

Fig. 2. lithology of five wells within the study area (L.D.2, L.D.3, L.D.4) Bartella, (L.D.1) Karamless, (L.D.5) Qaraqosh, the upper part of the aquafer represents by quaternary deposits, while, Injana Formation begins when the absence the last gravel layers 


\subsection{Depth to Groundwater}

The depths are affected by the topography of the area and the human activities represented by the extraction of groundwater. The depth considered as one of the influencing factors controlling the drilling methods, the type of pumps and the dimensions of wells. The depths to groundwater in the area were measured using the ground water depth detector in 48 of the 55 wells, and it is ranged from 5 meters in the center of the study area, and increased in all directions to reached 45 meters approximately, (Fig. 3). The seasons of heavy rains and floods caused by the rains storms, raise the water table to near the ground surface due to the absence of sewage drainage systems. It is noticed from the map of groundwater depths that it is consistent with the map of groundwater table, (Fig. 3) as the area that has high groundwater table corresponds to a certain extent with the area with lower depths on the map of groundwater depths.
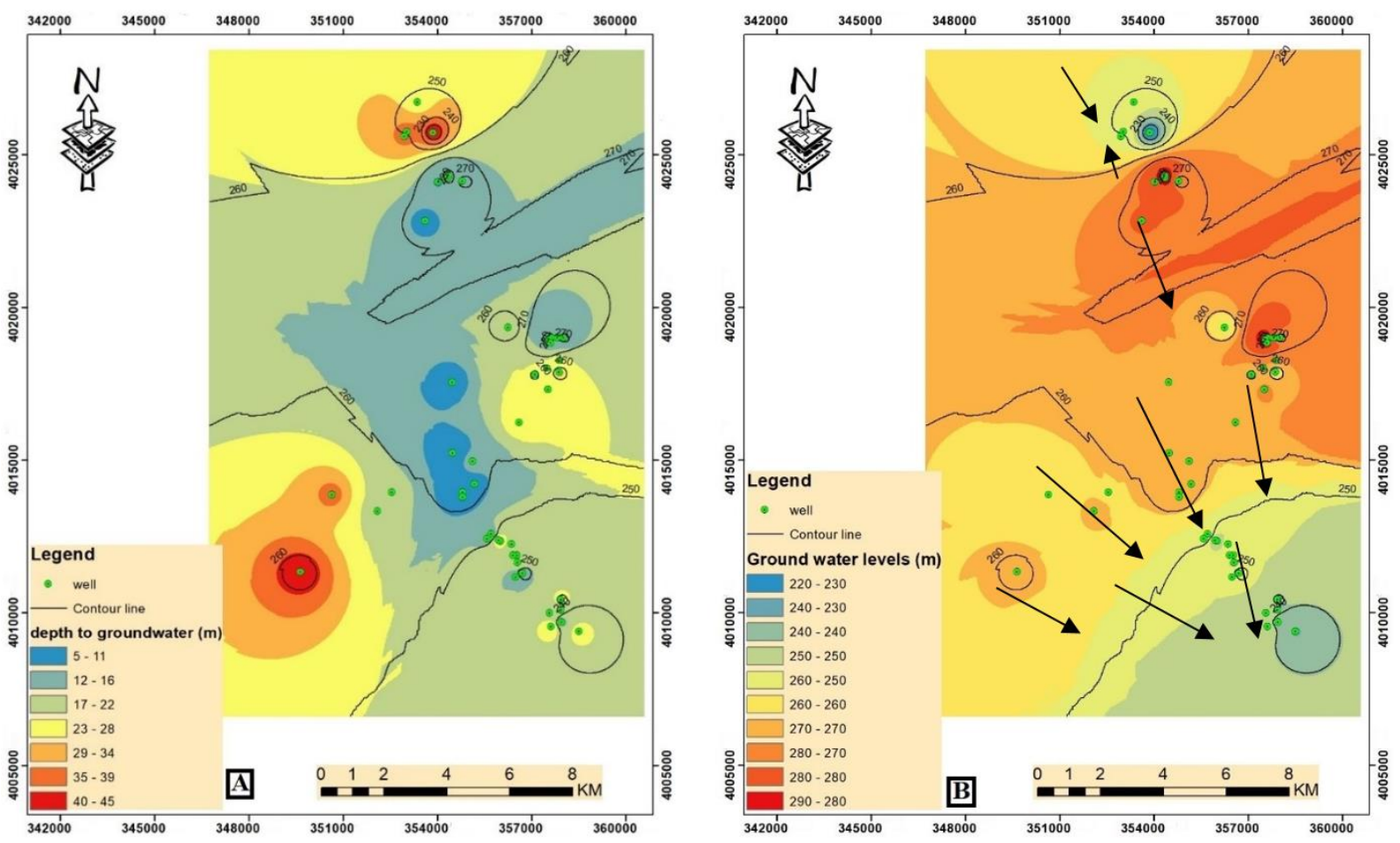

Fig. 3. Maps representing A. the depths of the groundwater; B. the groundwater levels and flow net in the study area

\subsection{Groundwater Table and Flow Direction}

Groundwater table is very importance in the groundwater studies, as they are one of the controlling factors in groundwater extraction, and determining the directions of its movement and natural drainage. The elevation of ground surface from sea level was measured using Digital Elevation Model (DEM), and the groundwater table in the wells ranged from 234-278.5 meters above sea level.

The coordinates of the wells locations were determined using GPS the data of the water table and coordinates of the wells were inputted into ARC GIS software (V10.3) to draw the contour map of ground water table in the area, (Fig. 3). Flow net map gives information about the gradient of water table and the direction of groundwater flow and it is known that groundwater moves from high-pressure towards low-pressure levels. The groundwater movement is controlled by the hydraulic gradient, and 
hydraulic conductivity within the groundwater aquifer as well as affected by other factors, such as porosity, the nature of aquifer (confined or unconfined), the recharge and discharge areas.

The groundwater table equipotential map was plotted for the study area, to determine the direction of groundwater movement and natural drainage. Thus, the direction of groundwater flow lines dawn perpendicular to the equipotential lines (Sanders, 1998), as in Fig. 3. It was found that the direction of groundwater movement is in the center and south of the area towards the Balawat area southeast of Qaraqosh. While the flow in northern part is towards Khazna Tabba area north of Bartella.

The trend of groundwater flow corresponds the direction of the surface drainage system (valleys) and the topographical slope, and compatible with the geomorphological concepts that the high lands in general represent the recharge areas and low lands as discharge areas. It has been observed that there are local changes in the directions of flow, due to several reasons, including the variation in groundwater pumping from one area to another (Al-Taweel, 1983), the heterogeneity of the porous media, the variation of hydraulic properties in terms of permeability and porosity, or due to the presence of abnormal recharge.

\subsection{Hydraulic Gradient}

Hydraulic conductivity is defined as the ability of aquifer materials to transfer water (Al-Gburi, and Al-Tamimi, 2020). The hydraulic gradient was calculated at selected sites in the study area, it was about $0.022,0.003$ and 0.008 in north, middle and south of the area, respectively.

\subsection{Pumping Test Analysis Methods}

In order to identify the best methods for processing pumping data and evaluating hydraulic properties, it is necessary to recognize the geological and hydrogeological conditions of an aquifer, in other word, the availability of information such as the type of the aquifer, flow circumstances, presence or absence of monitoring wells, hydrogeological boundaries and well pumping rates. The purpose of pumping test experiments is to obtain hydraulic properties that are useful in solving complex problems of wells in terms of well productivity, well efficiency, groundwater table, and groundwater flow. This is done by pumping the water from the aquifer for a certain period of time and with a constant pumping rate, and the drawdown of groundwater table is measured in the nearby observation wells, the measuring continues until the steady state of groundwater table (the constant level) (El-Rawy, and De Smedt, 2020). Two methods were used to analyze pumping test, they are Theis method and Cooper-Jacob method (Kruseman and Deridder, 1979).

\subsection{Pumping Wells and the Pumping Test Analysis:}

The pumping test was carried out in the study area at two sets of wells only because the absence of more suitable sets for this experiment, monitoring and observation wells selected for each sets. The results of hydraulic properties estimated by pumping test may represent multilayer groundwater aquifer, due to the difficulties of separating the aquifers from each other, during the pumping test and the lack of ideal conditions for this method, and these wells are:

1. A well (Saint Barbara Monastery / Karamless village, east of the study area).

2. A well (afram Rafu Shito / Qaraqosh village, south of the study area).

The pumping test data were processed in the Aquifer Win 32 software as in the following:

\section{6. 1. The well of the Monastery of Saint Barbara}

This well is located in the east of the study area (Karmless district), with the monitoring well 14 meters apart. The depth groundwater in the monitoring well is (22.35) meters, and the total depth of this 
well is (180) meters. The pumping process was carried out on 21/10/2020, with pumping rate of (8) bThen the pumping was stopped when the level had steadied in the monitoring well Since the groundwater level reach the depth to groundwater was (17.96) $\mathrm{m}$. From the processing of pumping data, it was found that the Transmissivity was $107.671 \mathrm{~m}^{2} /$ day by Theis, and $100.682 \mathrm{~m}^{2}$ /day by CooperJacob methods, (Fig. 4). Moreover, the hydraulic conductivity of saturated thickness (157.65) m was reached $0.683 \mathrm{~m} /$ day by Theis method, and $0.639 \mathrm{~m} /$ day by Cooper-Jacob methods, which were conducted in the same conditions for the study area, as for the storage coefficient, it reached 0.0023 by Theis and 0.0020 by the Cooper-Jacob methods (Table 2). Which is very close to that was mentioned by Todd (2005) regarding to the storage coefficient of confined groundwater aquifers that consist of fine grain clastic sediments between silt and fine sand which is ranged between confined and unconfined groundwater aquifers. From the curve of the relationship between time and drawdown in Fig. 4 it was found that this curve is similar to the curves of semi-confined aquifer by Hantoush (Todd, 2005). It was observed that the points represent the field data fall on the standard curves except for those that represent the beginning of pumping due to the effect of well storage. The great similarity in the values of hydraulic parameters by different methods confirms the accuracy of the results.

Table 2. The results of the pumping test of the monastery of Saint Barbara well by Theis and CooperJacob method

\begin{tabular}{lcc}
\hline \multicolumn{1}{c}{ Parameter } & Theis Method & Cooper-Jacob Method \\
Transmissivity (T) & $107.671 \mathrm{~m}^{2} / \mathrm{d}$ & $100.682 \mathrm{~m}^{2} / \mathrm{d}$ \\
Hydraulic Conductivity (K) & $0.683 \mathrm{~m} / \mathrm{day}$ & $0.639 \mathrm{~m} / \mathrm{day}$ \\
Storage Coefficient (Sc) & 0.0023 & 0.0020 \\
Radial Distance & $14 \mathrm{~m}$ & $14 \mathrm{~m}$ \\
Pumping Rate & $81 / \mathrm{sec}$ & $81 / \mathrm{sec}$ \\
\hline
\end{tabular}
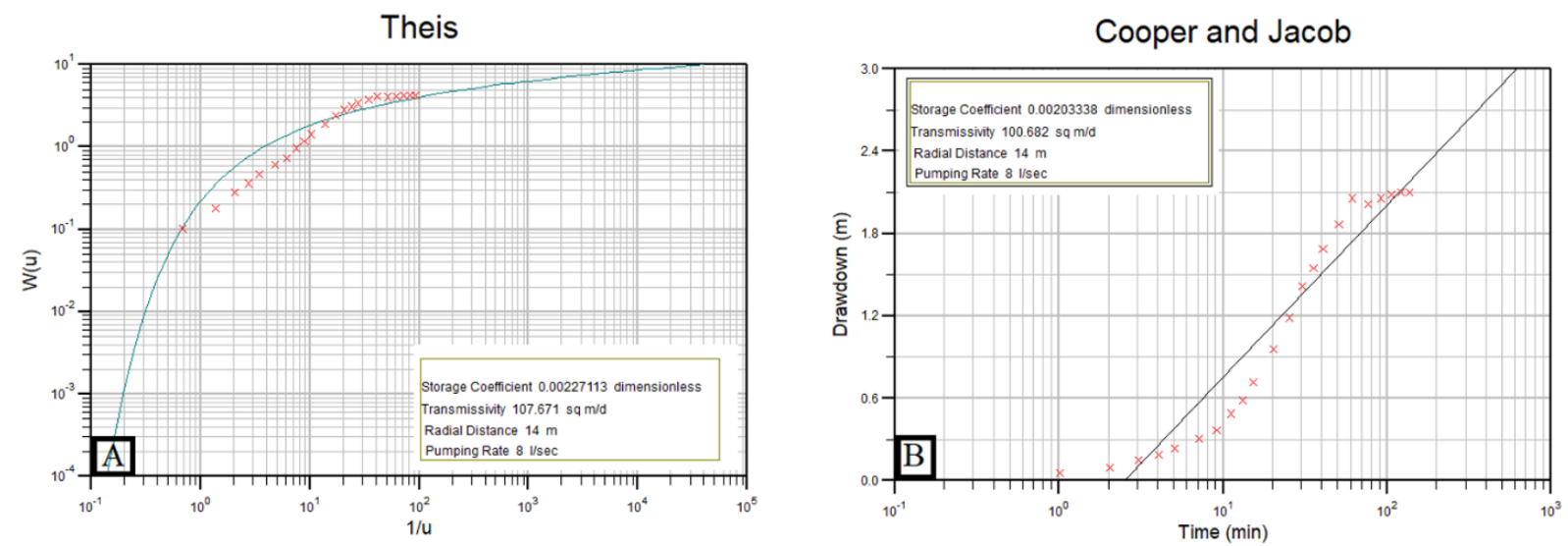

Fig. 4. The results of the pumping test by Theis method on the (A) and Cooper-Jacob on the (B) the well of the monastery of Saint Barbara

\section{6. 2. The well of Afram Raffo Shitto farm}

This well is located to south of the study area (Qaraqosh district), with the monitoring well 18 meters apart. The depth groundwater in the monitoring well is 11.93 meters, and the total depth of this well is 83 meters. The pumping process was carried out on 21/10/2020, with pumping rate of $71 / \mathrm{sec}$., the pumping continued for 90 minutes, the time and corresponding drawdown were monitored. Then the pumping was stopped when the level had steadied in the monitoring well Since the groundwater level reach the depth to groundwater was $17.96 \mathrm{~m}$. From the processing of pumping data, it was found 
that the Transmissivity was $87.1685 \mathrm{~m}^{2} /$ day by Theis, and $88.1004 \mathrm{~m}^{2} /$ day by Cooper-Jacob methods, (Fig. 5). Moreover, the hydraulic conductivity of saturated thickness (71.07) $\mathrm{m}$ was reached $1.23 \mathrm{~m} / \mathrm{day}$ by Theis method, and $1.24 \mathrm{~m} /$ day by Cooper-Jacob methods which were conducted in the same conditions for the study area, as for the storage coefficient, it reached 0.00135 by Theis and 0.00115 by the Cooper-Jacob methods. (Table 3). Which is very close to that was mentioned by Todd (2005) regarding to the storage coefficient of confined groundwater aquifers that consist of fine grain clastic sediments between silt and fine sand which is ranged between confined and unconfined groundwater aquifers. From the curve of the relationship between Time and Drawdown (Fig. 5), it was found that this curve is similar to the curves of semi-confined aquifer by Hantoush (Todd, 2005). It was observed that the points represent the field data fall on the standard curves except for those that represent the beginning of pumping due to the effect of well storage. The great similarity in the values of hydraulic parameters by different methods confirms the accuracy of the results.

Table 3. the results of the test pumping of the well of Afram Raffo Shitto farm by Theis and CooperJacob method

\begin{tabular}{lcc}
\hline Parameter & Theis Method & Cooper-Jacob Method \\
Transmissivity (T) & $87.1685 \mathrm{~m}^{2} / \mathrm{d}$ & $88.1004 \mathrm{~m}^{2} / \mathrm{d}$ \\
Hydraulic Conductivity (K) & $1.23 \mathrm{~m} /$ day & $1.24 \mathrm{~m} / \mathrm{day}$ \\
Storage Coefficient (Sc) & 0.00135 & 0.00115 \\
Radial Distance & $18.25 \mathrm{~m}$ & $18.25 \mathrm{~m}$ \\
Pumping Rate & $71 / \mathrm{sec}$ & $7 \mathrm{l} / \mathrm{sec}$ \\
\hline
\end{tabular}
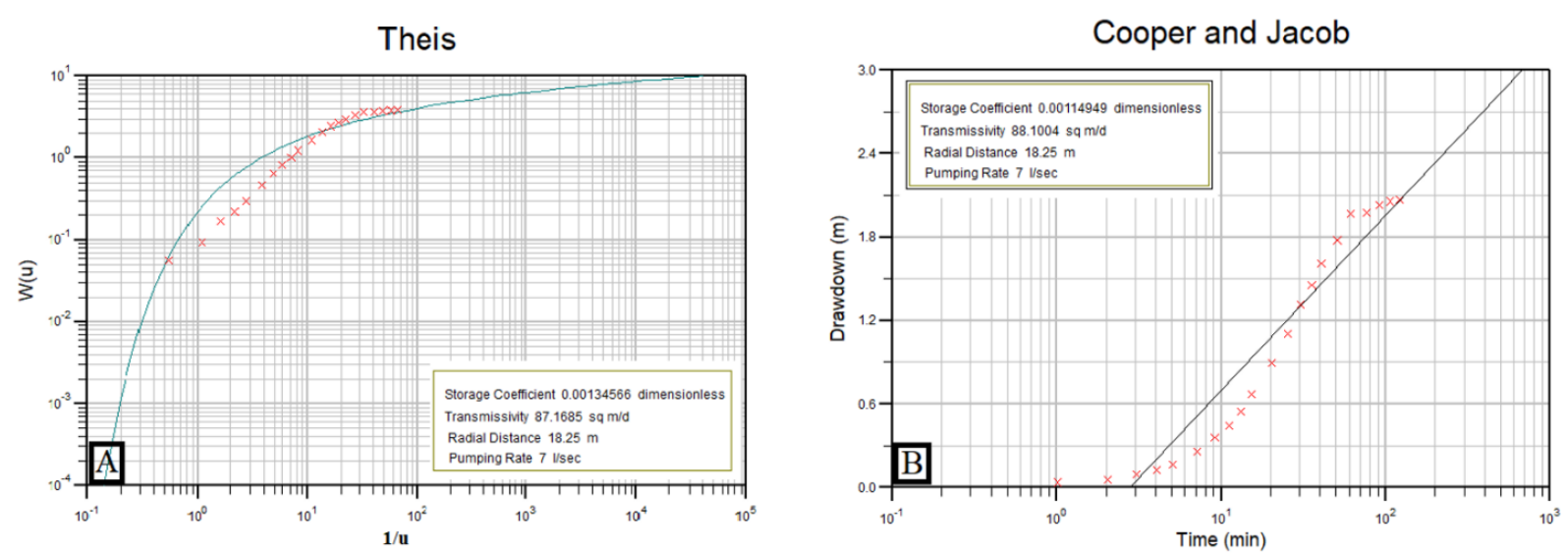

Fig. 5. The results of the test pumping by Theis method on the (left) and Cooper-Jacob on the (right) of the well of the farm of Afram Raffo Shitto

\subsection{Total Dissolved Solid (TDS)}

Total dissolved solids generally reflect the amount of dissolved minerals content in the water, especially salts, the origin of these salts may be deduced from the lithological description of the aquifers of groundwater (Awadh and Ahmed, 2013), this feature indicate the hydrogeological system and the types of the groundwater aquifers. It was noticed from that the concentrations of total dissolved solids raised to more than $3500 \mathrm{ppm}$ in the mid of the study area and decreased towards all directions to reach $250 \mathrm{ppm}$. This wide variation in salinity may be because that the wells in the central region penetrates saline groundwater aquifers, and it is most likely the layers of Al-Fat'ha Formation, which is in hydraulic contact with the main aquifer of the Injana Formation. A high concentration of TDS may cause adverse effects on plant growth and soil quality. Its concentrations are varied according to the geological 
background, the difference of rock materials solubility, and the period that the water in contact with the rocks.

\section{Conclusions}

The geology of the region controls the hydrogeological system of the basin, the sediments of the Quaternary (alluvial fans and river terraces) represented a secondary aquifer. While the Injana formation which contains a succession sand, silt and clay represent the main confined - semiconfined aquifer due to the presence of impermeable clay layers. The results of storage coefficient indicate the conditions of the confined to semi-confined aquifers. Structural phenomena controlled the basin's characteristics and its hydrogeological boundaries, as in the case of Ayn al-Safra and Bashiqa anticlines, which are NWSE strike, and represent the eastern and northeastern boundaries of the study area, which is recharge the studied area, while the western hydrogeological boundary represented by Tigris River. The depths of the groundwater in the study area varied from $5 \mathrm{~m}$ in the center to $45 \mathrm{~m}$ in the north and south. The measurements of groundwater table indicate that it reaches to about $278.5 \mathrm{~m}$ (a.s.l) in the center and decreased gradually to $234 \mathrm{~m}$ (a.s.l) in the north and south. The general direction of groundwater movement in the aquifer is from the recharge area adjacent to Bashiqa, towards the south, which is correspond to the direction of the surface topographical slope in the area, with the presence of local movement directions resulted by pumping from the aquifer or due to the heterogeneity of the porous medium. The wide variation in salinity may be because that wells in the central area penetrate groundwater aquifers of a saline lithology as in Al-Fat'ha formation, which is in hydraulic contact with the main aquifer represented by Injana formation.

\section{Acknowledgements}

The authors are very grateful to the Editor in Chief Prof. Dr. Salih M. Awadh, the Secretary of Journal Mr. Samir R. Hijab. and the Technical Editors for their great efforts and valuable comments.

\section{References}

Al-Taweel, B. H., 1983. Soil Genesis in Relationship to Groundwater Regimes in Hummocky Groundwater Movalne Area Near Hamlota Manitoba, Ph, D. Thesis, Department of Soil Science University of Manitoba, $220 \mathrm{pp}$.

Awadh, S.M., Al-Mimar, H. and Yaseen, Z.M., 2020. Groundwater availability and water demand sustainability over the upper mega aquifers of Arabian Peninsula and west region of Iraq. Environment, Development and Sustainability, pp.1-21.

Awadh, S.M. and Ahmed, R.M., 2013. Hydrochemistry and pollution probability of selected sites along the Euphrates River, Western Iraq. Arabian Journal of geosciences, 6(7), pp.2501-2518.

El-Rawy, M., and De Smedt, F., 2020. Estimation and mapping of the transmissivity of the Nubian sandstone aquifer in the Kharga Oasis, Egypt, Water, 12 (2), 604.

Kruseman, G.P. and Deridder, N.A., 1979. Analysis and Evaluation of Pumping test Data, Int. Inst. Forland Reclamation and Improvement, $209 \mathrm{pp}$.

Kruseman, G.P. and deRidder, N.A., 1990. Analysis and Evaluation of Pumping Test Data, Second Edition, ILRI publication 47, International Institute for Land Reclamation and Improvement, The Netherlands, $377 \mathrm{pp}$.

Lamei, P. van der Zaag, E. von Münch, 2008. Basic cost equations to estimate unit production costs for RO desalination and long-distance piping to supply water to tourism-dominated arid coastal regions of Egypt, Desalination, 225(1-3), 1-2.

Al-Gburi, M. R., and Al-Tamimi, O. S., 2020. Groundwater vulnerability assessment using drastic model of up Al-Khassa Dam, Sub-Basin, Kirkuk, Ne Iraq, Iraqi Geological Journal, 53( 2E), 12-24.

Pangarkar, B. L., Thorat, P.V., Parjane, S.B., Abhnag, R.M., 2010. Performance evaluation a vacuum membrane distillation for desalination dy using a flat sheet membrane, desalination and water treatment, 21, 328-334. 
Al-Kubaisi, Q. Y., Hussain, T. A., and Rasheed, A. A., 2018. Hydraulic properties of the Bai-Hassan Aquifer in Tuz-Khurmatu, Salahaddin, Iraq, Iraqi Geological Journal, 51( 1), 113-129.

Rathod, K.S. and Rushton, K.R., 1984. Numerical methods of pumping test only using microcomputer, groundwater, 29(4), 499-515.

Reed, J.E., 1980. Type Curves for Selected Problems of Flow to Wells in Confined Aquifers, USGS Techniques of Water-Resources Investigations, Book 3, 106.

Richard M.Y., Leon J.K., David R.S., Adel E. H., Paul M. H., Cheryl A. B., Stephen M. W., and James E. R., 2019. Characterization and Occurrence of Confined and Unconfined Aquifers in Quaternary Sediments in the Glaciated Conterminous United States, USGS Scientific Investigations Report 2018-5091 Version 1.1, 104.

Sanders, L.L., 1998. A manual of Field Hydrogeology, Prentice-Hall, 381pp.

Schaaf, S.V., 2004. A Single well pumping and recovery test to measure in situ Acrotelm Transmissivity in Raised Bogs. Tournal of Hydrogeology, 209, 152-160.

Theis, C.V., 1935. The Relation between the Lowering of the Piezometric Surface and the Rate and Duration of Discharge of a Well Using Groundwater Storage, Geophysics, 16, 519-524.

Todd, D.K., 2005. Groundwater Hydrology (3 edition), John Wiley and Sons New York, USA, 650.

USEPA, United States Environmental Protection Agency, 2012. Drinking water health advisory for manganese, U.S. Environmental Protection Agency, spring, Report EPA-822-S-12-001.

World Health Organization (WHO), 2017. Guidelines for Drinking-water Quality. 4th ed, incorporating the first addendum. Brazil, World Health Organization, 518.

Yajing and Kunpeng tian, 2009. Application of vacuum mem brane distillation in water treatment, Journal of sustainable Development, 2(3), 183-186. 